\title{
Correlation of Radiomorphometric Indices of the Mandible and Biochemical Parameters in Patients with Secondary Hyperparathyroidism Due to Chronic Kidney Disease
}

\author{
Hébel Cavalcanti Galvão

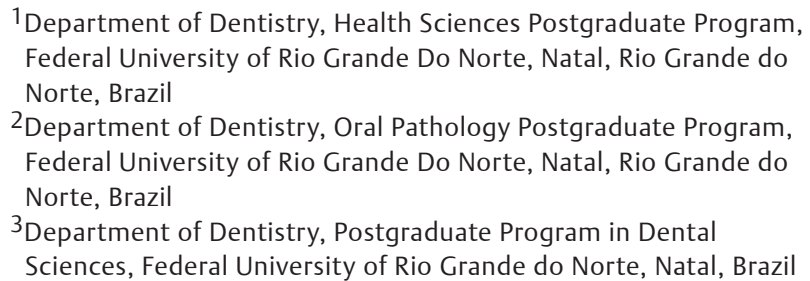

Stenio Medeiros Queiroz ${ }^{1}$ Ana Luiza Dias Leite De Andrade ${ }^{2} \quad$ Patrícia Teixeira De Oliveira ${ }^{3}$

Paulo Raphael Leite Maia ${ }^{3}$ Ângelo Giuseppe Roncalli Da Costa Oliveira ${ }^{3}$ Roseana De Almeida Freitas ${ }^{2}$

\begin{abstract}
Address for correspondence Hébel Cavalcanti Galvão, Department of Dentistry, Health Sciences Postgraduate Program, Federal University of Rio Grande Do Norte,Natal, Rio Grande do Norte, Caixa postal 1524, CEP 59078-970, Brazil (e-mail: hebel.galvao@yahoo.com.br).
\end{abstract}

Eur J Dent 2019;13:303-309

\begin{abstract}
Objective The aim was to correlate radiomorphometric indices and biochemical analyses as an auxiliary method in bone evaluation in male and female patients with chronic kidney disease-mineral and bone disorder (CKD-MBD) and controls.

Materials and Methods Nine radiomorphometric indices and four biochemical parameters were obtained: mental index (MI), height at the mental foramen, total mandibular height (THM), panoramic mandibular index (PMI), original height of the mandible, alveolar bone resorption, distance from the mental foramen to the alveolar bone crest (MF-ABC), mandibular cortical index $(\mathrm{MCl})$, trabecular bone pattern, para-

Keywords thyroid hormone $(\mathrm{PTH})$, calcium $(\mathrm{Ca})$, phosphorus $(\mathrm{P})$, and $\mathrm{Ca} \times \mathrm{P}$ product $(\mathrm{Ca} \times \mathrm{P})$.

- chronic kidney disease

- panoramic radiography

- radiomorphometric indices

- renal osteodystrophy

- secondary

hyperparathyroidism

Statistical Analysis The Mann-Whitney U-test, chi-squared test, and Spearman's correlation were applied at a significance level of $95 \%$.

Results There was a moderate negative and significant correlation between MI, PMI, and PTH in female patients with CKD-MBD as well as between THM, MF-ABC, and Ca $\times$ P. The $\mathrm{MCl}$ and trabecular bone pattern indicated altered bone quality in male patients.

Conclusions The radiomorphometric evaluation was an auxiliary, noninvasive method to detect possible alterations in the cortex and mandibular bone trabeculation in male and female patients with CKD-MBD.
\end{abstract}

\section{Introduction}

Parathyroid hormone (PTH) is one of the systemic factors that influence the rate of osteoclast resorption and its levels progressively increase concomitant with the installation of chronic kidney disease (CKD), causing secondary hyper-

DOI https://doi.org/

$10.1055 / \mathrm{s}-0039-1688738$

ISSN 1305-7456. parathyroidism (SHPT), ${ }^{1,2}$ Some authors who correlated the trabecular bone pattern of the mandible affirmed that the radiomorphometric indices correlated to plasma levels of PTH may be a useful tool to identify the effects of osteoporosis due to SHPT in patients with CKD-mineral and bone disorder (CKD-MBD). ${ }^{3-7}$ 
Thus, objective of this study was to correlate serum PTH, $\mathrm{Ca}, \mathrm{P}$, and $\mathrm{Ca} \times \mathrm{P}$ levels with radiomorphometric indices of the mandible, used as an auxiliary means for the diagnosis of osteoporosis, for the identification of bone alterations in male and female patients with CKD (glomerular filtration rate $<15 \mathrm{~mL} / \mathrm{min} / 1.73 \mathrm{~m}^{2}$ ) and severe SHPT (PTH > $600 \mathrm{pg} / \mathrm{mL}$ ), all with CKD-MBD compared with healthy patients in the same age group, gender, race, and periodontal conditions.

\section{Materials and Methods}

\section{Patients}

This was an observational, longitudinal, prospective, case-control study. The sample consisted of 66 patients with CKD-MBD (38 men and 28 women) in Stage 5 of the CKD-MBD (glomerular filtration rate $<15 \mathrm{~mL} / \mathrm{min} / 1.73 \mathrm{~m}^{2}$ ). They were recruited from the Kidney Transplant Center of the University Hospital Onofre Lopes (Rio Grande do Norte, Brazil). The following inclusion criteria were applied: diagnosis of SHPT with serum PTH levels $\geq 600 \mathrm{pg} / \mathrm{mL}$ for at least 3 months; hemodialysis for at least 5 years; presence of at least three lower premolars on both sides; replacement therapy with calcium binders; vitamin D and phosphate according to the needs of each patient, and without history of parathyroidectomy. The control group consisted of 132 healthy individuals who sought the department of dentistry for treatment. All were matched (two to one) with the same race (Caucasian or Afro-descendant), gender, age ( \pm 5 years), and similar periodontal conditions (none, mild, moderate, and severe) and had at least three lower premolars. Women from both groups had no history of hysterectomy. The study was conducted according to the guidelines of the Declaration of Helsinki and was approved by the Ethics Committee of the Federal University of Rio Grande do Norte (protocol number: 1.053.639).

\section{Image Acquisition}

Panoramic digital radiographs were purchased by a technician with 5 years of experience using Carestream KODAK 8000c in the department of dentistry. All participating patients were positioned on the device following the manufacturer's positioning recommendations. Three experienced oral and maxillofacial radiologists who were unaware of patient identification information analyzed the data. Calibration of the quantitative and qualitative parameters was done through five panoramic radiographs. Divergent results were discussed until consensus was reached.

\section{Measurements}

Quantitative indexes used were as follows ( - Fig. 1): mental index (MI), ${ }^{8}$ height at the mental foramen (HMF), ${ }^{9,10}$ total mandibular height (THM) obtained as the distance from the cementoenamel junction of the premolar positioned more inferiorly in relation to the occlusal plane to the lower border of the mandibular cortex, ${ }^{11}$ the panoramic mandibular index (PMI) calculated by the following equation $\mathrm{PMI}=\mathrm{MI} / \mathrm{HMF}^{9-12}$ the original height of the mandible (OHM) $\mathrm{Z}$ using the formula $\mathrm{OHM}=2.9 \times \mathrm{HMF}$ according to Wical

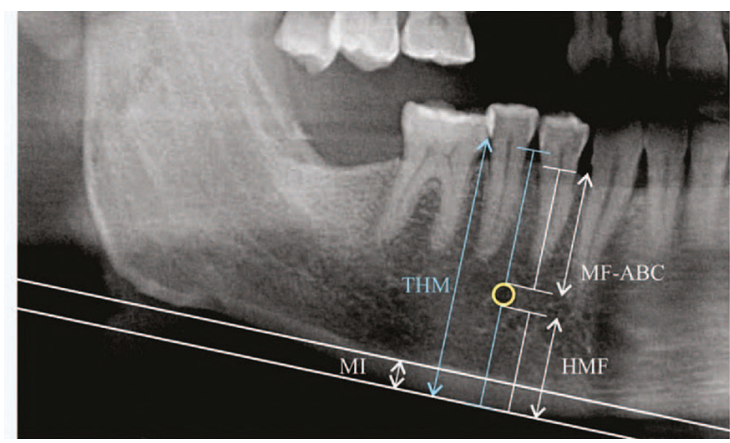

Fig. 1 Measurements: Distance between the upper border of the MF-ABC; HMF; THM; MI; panoramic mandibular index. HMF, height of the mental foramen; MF-ABC, mental foramen to the upper border of the alveolar bone crest; MI, mental index, THM: Total height of the mandible.

and Swoope, ${ }^{12}$ the mandibular bone loss calculated using the degree of alveolar bone resorption (ABR) through the equation $\mathrm{ABR}=(\mathrm{OHM}-\mathrm{THM}) / \mathrm{OHM})$, and the distance from the upper border of the mental foramen to the upper border of the alveolar bone crest (MF-ABC). ${ }^{11}$ The following qualitative variables were analyzed: mandibular cortical index (MCI) and trabecular bone pattern ( $\mathbf{- F i g s .} \mathbf{2}$ and $\mathbf{3}$, respectively).,6,7

\section{Biochemical Parameters}

In patients with CKD-MBD, biochemical parameters were obtained at baseline and after 3 months. The mean of these two values was used. The dosages of PTH, Ca, P, and $\mathrm{Ca} \times \mathrm{P}$ were obtained only once for the control group and the reference values were 12 to $60 \mathrm{pg} / \mathrm{mL}, 9$ to $11 \mathrm{mg} / \mathrm{dL}, 2.5$ to $4.8 \mathrm{mg} / \mathrm{dL}$, and $<55 \mathrm{mg}^{2} / \mathrm{dL}^{2}$, respectively.

\section{Statistical Analysis}

For intra- and interobserver agreement, the kappa index was used with a 1-week interval showing substantial agreement.

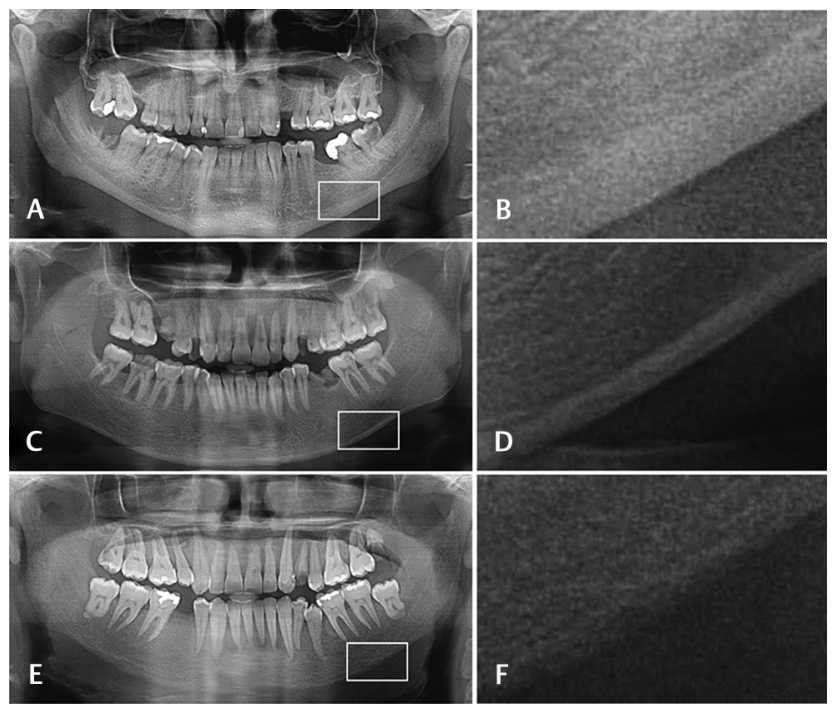

Fig. 2 Normal cortex-the endosteal margin of the cortex was even and sharp on both sides (A and B). C2: Mildly-to-moderately eroded cortex-The endosteal margin showed semilunar defects (lacunar resorption) or it appeared to form endosteal cortical residues (C and D). C3: severely eroded cortex-The cortical layer formed heavy endosteal cortical residues and it was clearly porous ( $\mathbf{E}$ and $\mathbf{F}$ ). 


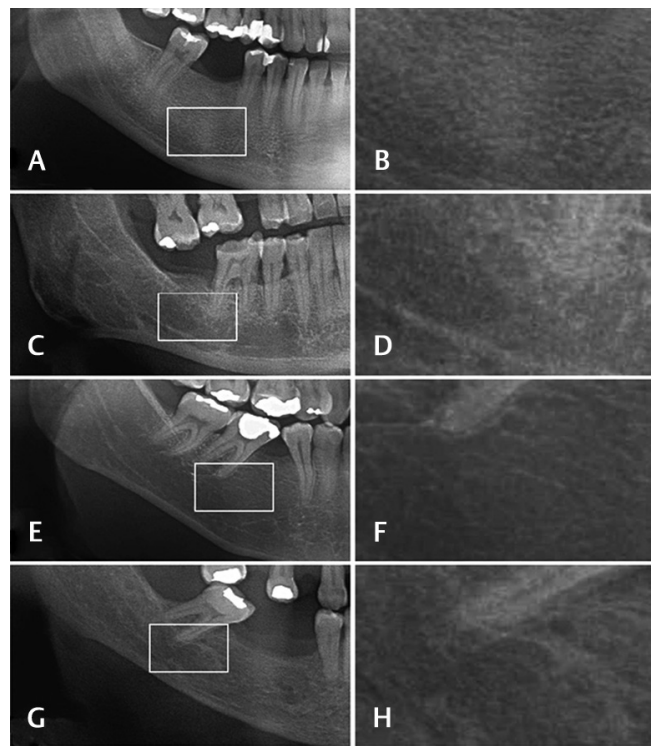

Fig. 3 Classification of trabecular bone pattern. Dense homogeneous trabeculation: many trabeculae connected to each other and an impression of small/few marrow spaces (A and $\mathbf{B})$. Heterogeneous trabeculation: when both dense and sparse trabeculation is found and when there are difficulties sorting the trabecular pattern under dense or space (C and $\mathbf{D})$. Sparse trabeculation: fewer trabeculae, larger marrow spaces, and an impression of more radiolucency in the image ( $\mathbf{E}$ and $\mathbf{F}$ ). Specifically, for secondary hyperparathyroidism, the category sparse with ground-glass appearance ( $\mathbf{G}$ and $\mathbf{H})$.

The Kolmogorov-Smirnov test was used to verify the normality of the data, the nonparametric Mann-Whitney $\mathrm{U}$ test to compare two independent samples, and the chi-squared test for the analysis of the qualitative variables. Spearman's correlation was used for the quantitative variables. A significance level of $5 \%(p<0.05)$ was adopted for all tests.

\section{Results}

The present sample consisted of 66 patients with CKD-MBD and 132 controls with a mean age of 40.21 and 41.06 years, respectively, including 38 males with a mean age of 41.21 years (range: $21-71$ years) and 28 female patients with a mean age of 38.85 years (range: $20-59$ years). In women, mean age of menarche was $12.61( \pm 2.6)$ years and mean age at menopause was 46.7 years $( \pm 4.1)$. Fifty-seven patients with CKD-MBD were Caucasian and nine were Black. The mean duration of hemodialysis was 7.37 years in male patients and 6.32 years in female patients. - Tables 1 to 3 show the results of the associations made. In female patients with CKD-MBD, moderate negative and significant correlations were observed between MI/PMI and PTH $(r=-0.55 ; p \leq 0.01 / r=-0.47 ; p=0.01$, respectively) and THM/Ca $\times \mathrm{P}(r=-0.38 ; p=0.04)$.

\section{Discussion}

Although it is questionable to choose a dynamic biochemical marker with a very short half-life, such as PTH to correlate with two-dimensional radiographs, and considering that bone remodeling lasts around 3 to 6 months, we select patients who maintained $\mathrm{PTH} \geq 600 \mathrm{pg} / \mathrm{mL}$ results during at least 3 months. Dental panoramic radiography is a useful imaging technique that permits the dentist to evaluate the entire dentition and mandibular bone which, like other bones of the body, can be affected by systemic and local diseases or medical treatment, causing total tooth loss. ${ }^{13-15}$ The use of panoramic radiography to predict mandibular bone mineral density also permits to determine the loss of skeletal bone mineral density in general. Approximately, $90 \%$ of CKD cases are involved in mandible bone changes. ${ }^{14}$ In addition, the bone loss at peripheral sites (mainly cortical bone) differs from the bone loss at axial sites, especially spongy bone. ${ }^{16-18}$ Radiomorphometric indices together with clinical-epidemiological data can be used as prognostic markers of bone loss. However, there is no consensus among researchers regarding the use of panoramic radiograph as a reliable tool for the diagnosis of osteoporosis., ${ }^{4,810,19}$ In this respect, studies indicate the MI and MCI to be the best parameters for the identification of osteoporosis on panoramic radiographs and reference values for mandibular cortical thickness of $3.0,3.15$, and $3.5 \mathrm{~mm}$ have been suggested for the study of osteoporosis., ${ }^{2,4}$

In our study, CKD-MBD patients had lower indices of MI and PMI in women and were statistically significant than in male patients and in control patients indicating bone loss. According to some authors, the world average age of menopause is 50.7 years. ${ }^{20}$ Early menopause detected at 46.7 years ( \pm 4.1 ) may have been the main factor contributing to the rapid decline in skeletal and maxillary bone mineral density. ${ }^{20,21}$ According to Klemetti et $\mathrm{al}^{4}$ and Ghapanchi et al, ${ }^{14}$ panoramic radiographs of postmenopausal women with CKD showed a lower mandibular cortex thickness compared with healthy individuals in such a way that this parameter may help to diagnose osteoporosis in these patients.

It is known that SHPT has an anabolic effect on trabecular bone and a catabolic effect on cortical bone. ${ }^{17}$ Studies associating MI with PTH levels showed a reduction in the mandibular cortex with the progression of SHPT.,3 In the present study a moderate and significant negative correlation was observed between MI and PTH, as well as between PMI and PTH in female patients. These results demonstrate that women tend to have a lower bone mineral density than men with SHPT in this age range, probably due to the criteria and factors such as race, genetic factors, smoking, drug use, age at menarche, menstrual cycle, nutrient intake, physical activity, and frequent amenorrhea, as well as the effect of hormonal changes caused by menopause with the removal of estrogen in postmenopausal women. The radiomorphometric indices can be used for the screening of these patients to prevent comorbidities associated with CKD, although few studies have shown male gender, age, and duration of dialysis to be aggravating factors of SHPT., 3, 18,22,23

An increase in serum $\mathrm{P}$ and $\mathrm{Ca} \times \mathrm{P}$ is significantly associated with the progression of CKD which is also associated with the morbidity and mortality of these patients, especially when related to cardiovascular events. ${ }^{1,24}$ An association was observed between THM and $\mathrm{Ca} \times \mathrm{P}$ as well as MF-ABC 
Table 1 Descriptive statistics and Mann-Whitney $U$ test for radiomorphometric indices and laboratory parameters for patients with chronic kidney disease-mineral and bone disorder and control group according to gender

\begin{tabular}{|c|c|c|c|c|c|}
\hline \multirow[t]{2}{*}{ Variables } & \multirow[t]{2}{*}{ Gender } & \multicolumn{2}{|c|}{ Patients with CKD-MBD } & \multicolumn{2}{|c|}{ Control group } \\
\hline & & Mean \pm SD & $p$-Value & Mean \pm SD & $p$-Value \\
\hline \multicolumn{6}{|c|}{ Radiomorphometric indices } \\
\hline \multirow[t]{2}{*}{ MI } & Male & $1.86 \pm 1.23$ & \multirow[t]{2}{*}{0.28} & $3.78 \pm 0.54$ & \multirow[t]{2}{*}{0.11} \\
\hline & Female & $1.63 \pm 1.22$ & & $3.61 \pm 0.63$ & \\
\hline \multirow[t]{2}{*}{$\mathrm{HMF}$} & Male & $8.89 \pm 1.70$ & \multirow[t]{2}{*}{0.39} & $10.16 \pm 1.30$ & \multirow[t]{2}{*}{$<0.01$} \\
\hline & Female & $8.60 \pm 1.53$ & & $9.24 \pm 1.30$ & \\
\hline \multirow[t]{2}{*}{ THM } & Male & $26.19 \pm 2.61$ & \multirow[t]{2}{*}{$0.01^{\mathrm{a}}$} & $27.42 \pm 2.50$ & \multirow[t]{2}{*}{$<0.01$} \\
\hline & Female & $24.02 \pm 3.39$ & & $24.91 \pm 1.76$ & \\
\hline \multirow[t]{2}{*}{ PMI } & Male & $0.21 \pm 0.15$ & \multirow[t]{2}{*}{0.34} & $0.38 \pm 0.07$ & \multirow[t]{2}{*}{0.30} \\
\hline & Female & $0.19 \pm 0.14$ & & $0.40 \pm 0.09$ & \\
\hline \multirow[t]{2}{*}{$\mathrm{OHM}$} & Male & $25.77 \pm 4.94$ & \multirow[t]{2}{*}{0.39} & $29.45 \pm 3.77$ & \multirow[t]{2}{*}{$<0.01$} \\
\hline & Female & $24.94 \pm 4.42$ & & $26.79 \pm 3.76$ & \\
\hline \multirow[t]{2}{*}{ ABR } & Male & $0.20 \pm 0.31$ & \multirow[t]{2}{*}{0.19} & $0.11 \pm 0.97$ & \multirow[t]{2}{*}{0.29} \\
\hline & Female & $0.11 \pm 0.09$ & & $0.12 \pm 0.08$ & \\
\hline \multirow[t]{2}{*}{ MF-ABC } & Male & $14.01 \pm 3.12$ & \multirow[t]{2}{*}{$0.04^{\mathrm{a}}$} & $14.36 \pm 2.17$ & \multirow[t]{2}{*}{0.02} \\
\hline & Female & $12.71 \pm 2.43$ & & $13.12 \pm 1.91$ & \\
\hline \multicolumn{6}{|c|}{ Laboratory parameters } \\
\hline \multirow[t]{2}{*}{ PTH } & Male & $944.71 \pm 278.58$ & \multirow[t]{2}{*}{0.13} & $15.61 \pm 4.09$ & \multirow[t]{2}{*}{0.10} \\
\hline & Female & $1142.14 \pm 483.52$ & & $18.88 \pm 9.84$ & \\
\hline \multirow[t]{2}{*}{$\mathrm{Ca}$} & Male & $9.13 \pm 0.51$ & \multirow[t]{2}{*}{0.41} & $9.79 \pm 0.50$ & \multirow[t]{2}{*}{0.34} \\
\hline & Female & $9.06 \pm 0.98$ & & $9.88 \pm 0.60$ & \\
\hline$P$ & Male & $5.42 \pm 0.92$ & 0.50 & $3.47 \pm 0.51$ & 0.69 \\
\hline & Female & $5.60 \pm 1.11$ & & $3.43 \pm 0.57$ & \\
\hline $\mathrm{Ca} \times \mathrm{P}$ & Male & $49.11 \pm 10.14$ & 0.62 & $33.93 \pm 5.41$ & 0.81 \\
\hline & Female & $50.79 \pm 11.78$ & & $33.96 \pm 6.09$ & \\
\hline
\end{tabular}

Abbreviations: ABR, alveolar bone resorption; $\mathrm{Ca} \times \mathrm{P}$, calcium $\times$ phosphorus product; Ca, calcium; CKD-MBD, chronic kidney disease-mineral and bone disorder; HMF, height at the mental foramen; MF-ABC, mental foramen-alveolar bone crest; MI, mental index; OHM, original height of the mandible; P, phosphorus; PMI, panoramic mandibular index; PTH, parathyroid hormone; SD, standard deviation; THM, total height of the mandible. ${ }^{\mathrm{a}} \mathrm{p}<0.05$.

and $\mathrm{Ca} \times \mathrm{P}$ in female patients, and this result suggests that the duration of dialysis, which was longer in men compared with women, may be an important factor. The MCI and trabecular bone pattern indicated altered bone quality in male patients. Furthermore, according to some authors, Stage 5 CKD and severe SHPT manifest in a more aggressive manner in men. ${ }^{3,25,26}$

Renal osteodystrophy can manifest as low bone turnover disease or as a dynamic bone disease. A previous study evaluating the relationship between genders found higher mandibular bone mineral density in men and higher vertebral bone mineral density in women. ${ }^{26}$ In the present study, a significant difference in MF-ABC and THM was observed between male and female patients with CKD-MBD. As the incidence of periodontal disease is high in patients with CKD-MBD, MF-ABC measure was proposed to evaluate the rate of alveolar bone loss, since the THM measure extends to the cementoenamel junction and therefore does not cover the indicated area. In patients with aggressive periodontitis, it is essential to evaluate the degree of alveolar bone crest loss, and according to the literature reviewed here, this area is not analyzed by known radiomorphometric indices. In relation to the differences between genders, a previous study revealed that men showed a stable profile concerning the measurement of the cortical width at the mental foramen region, irrespective of an increase in age. ${ }^{27}$

In the present study, analysis of the $\mathrm{MCI}$ in the group of CKD-MBD patients according to gender showed that a higher number of the male patients were classified as C3. This finding agrees with some authors who found no difference in the distribution of men and women between the C2 and C3 categories of the $\mathrm{MCI} .{ }^{28}$ Those studies reported an age-related increase in the number of subjects classified as C3 and a higher incidence of C3 among women with osteoporosis, indicating that age is a strong factor associated with alterations in this index. On the other hand, our results showed a larger number of men with CKD-MBD who exhibited porosity in the mandibular cortical layer, in agreement with 
Table 2 Descriptive statistics and Mann-Whitney $U$ test for radiomorphometric indices and laboratory parameters for control group according to gender

\begin{tabular}{|c|c|c|c|}
\hline Variables & Gender & Mean \pm SD & p-Value \\
\hline \multicolumn{4}{|c|}{ Radiomorphometric indices } \\
\hline \multirow[t]{2}{*}{$\mathrm{MI}$} & Male & $3.78 \pm 0.54$ & \multirow[t]{2}{*}{0.10} \\
\hline & Female & $3.61 \pm 0.63$ & \\
\hline \multirow[t]{2}{*}{ HMF } & Male & $10.16 \pm 1.30$ & \multirow[t]{2}{*}{$<0.01^{\mathrm{a}}$} \\
\hline & Female & $9.24 \pm 1.30$ & \\
\hline \multirow[t]{2}{*}{ THM } & Male & $27.28 \pm 2.51$ & \multirow[t]{2}{*}{$0.01^{\mathrm{a}}$} \\
\hline & Female & $24.81 \pm 1.76$ & \\
\hline \multirow[t]{2}{*}{ PMI } & Male & $0.38 \pm 0.07$ & \multirow[t]{2}{*}{0.30} \\
\hline & Female & $0.40 \pm 0.09$ & \\
\hline \multirow[t]{2}{*}{$\mathrm{OHM}$} & Male & $29.45 \pm 3.77$ & \multirow[t]{2}{*}{$<0.01^{\mathrm{a}}$} \\
\hline & Female & $26.79 \pm 3.76$ & \\
\hline \multirow[t]{2}{*}{ ABR } & Male & $0.11 \pm 0.97$ & \multirow[t]{2}{*}{0.61} \\
\hline & Female & $0.12 \pm 0.08$ & \\
\hline \multirow[t]{2}{*}{ MF-ABC } & Male & $14.36 \pm 2.17$ & \multirow[t]{2}{*}{$0.02^{\mathrm{a}}$} \\
\hline & Female & $13.12 \pm 1.91$ & \\
\hline \multicolumn{4}{|c|}{ Laboratory parameters } \\
\hline \multirow[t]{2}{*}{ PTH } & Male & $15.61 \pm 4.09$ & \multirow[t]{2}{*}{0.10} \\
\hline & Female & $18.88 \pm 9.84$ & \\
\hline \multirow[t]{2}{*}{$\mathrm{Ca}$} & Male & $9.79 \pm 0.50$ & \multirow[t]{2}{*}{0.34} \\
\hline & Female & $9.88 \pm 0.60$ & \\
\hline \multirow[t]{2}{*}{$P$} & Male & $3.47 \pm 0.51$ & \multirow[t]{2}{*}{0.68} \\
\hline & Female & $3.43 \pm 0.57$ & \\
\hline \multirow[t]{2}{*}{$\mathrm{Ca} \times \mathrm{P}$} & Male & $33.93 \pm 5.41$ & \multirow[t]{2}{*}{0.80} \\
\hline & Female & $33.96 \pm 6.09$ & \\
\hline
\end{tabular}

Abbreviations: ABR, alveolar bone reabsorption; $\mathrm{Ca} \times \mathrm{P}$, calcium $\times$ phosphorus product; $\mathrm{Ca}$, calcium; HMF, height at the mental foramen; MF-ABC, mental foramen-alveolar bone crest; MI, mental index; OHM, original height of the mandible; P, phosphorus; PMI, panoramic mandibular index; PTH, parathyroid hormone; SD, standard deviation; THM, total height of the mandible. ${ }^{a} p<0.05$.

Table 3 Frequency distribution and chi-squared test for the variables mandibular cortical index and bone trabecular pattern according to the control group and group of patients with chronic kidney disease-mineral and bone disorder

\begin{tabular}{|l|l|l|l|}
\hline \multicolumn{2}{|l|}{} & Patients & \multicolumn{2}{l|}{ Control } \\
\hline MCI & $16.67 \%(n=11)$ & $87.12 \%(n=115)$ \\
\hline C1 & $37.88 \%(n=25)$ & $12.88 \%(n=17)$ \\
\hline C2 & $45.45 \%(n=30)$ & $0.00 \%(n=0)$ \\
\hline C3 & $7.59 \%(n=5)$ & $36.37 \%(n=48)$ \\
\hline Trabecular bone pattern & $30.34 \%(n=20)$ & $58.33 \%(n=77)$ \\
\hline Dense & $18.19 \%(n=12)$ & $5.30 \%(n=7)$ \\
\hline Heterogeneous & $43.94 \%(n=29)$ & $0.00 \%(n=0)$ \\
\hline Sparse &
\end{tabular}

Abbreviations: C1, normal cortex; C2, moderately eroded cortex; $C 3$, severely eroded cortex; $\mathrm{MCl}$, mandibular cortical index. ${ }^{a} p<0.05$. 
studies indicating age and male gender to be aggravating factors of SHPT. ${ }^{28}$ In addition, our sample included women with a younger mean age than in those studies, which also demonstrated that mandibular cortex resorption tends to increase with increasing PTH levels, irrespective of age and gender. ${ }^{2,5}$

The category "sparse with ground-glass appearance" was added to the classification of the "trabecular bone pattern" because of the particularities of SHPT in patients with CKDMBD. Since few studies have investigated the association of radiomorphometric indices with serum levels of $\mathrm{PTH}, \mathrm{Ca}$, and $\mathrm{P}$ in men and women with CKD and severe SHPT, this association was not found in the control group. ${ }^{3,25,29}$ In contrast, the present results demonstrated a higher frequency of the sparse with ground-glass appearance pattern in male patients compared with female patients. Our findings suggest that the mean long dialysis time may have been one of the causes of these results.

\section{Conclusions}

Significant associations were found (MI and PTH, PMI and $\mathrm{PTH}$, THM and $\mathrm{Ca} \times \mathrm{P}$, and MF-ABC and $\mathrm{Ca} \times \mathrm{P})$ in women as well as in men (MCI and bone trabecular pattern) with CKDMBD. In this sense, the radiomorphometric indices could contribute to the noninvasive bone diagnostic strategy, thus helping the treatment.

\section{Funding}

The authors thank the Foundation for Research Support of the State of Rio Grande do Norte, Brazil, for financial support, and all the hemodialysis centers that contributed to the study.

\section{Conflict of Interest}

None declared.

\section{References}

1 Kidney Disease: Improving Global Outcomes (KDIGO) CKDMBD Work Group. KDIGO clinical practice guideline update for the diagnosis, evaluation, prevention, and treatment of chronic kidney disease-mineral and bone disorder (CKD-MBD) foreword. Kidney Int Suppl 2017;7:1-59

2 Queiroz SM, Vasconcelos RG, Andrade AL, et al. Maxillary brown tumor associated with chronic kidney failure: a case report. J Bras Patol Med Lab 2013;49:424-428

3 Henriques JC, de Melo Castilho JC, Jacobs R, Amorim JB, Rosa RR, Matai CV. Severe secondary hyperparathyroidism and panoramic radiography parameters. Clin Oral Investig 2014;18(3):941-948

4 Klemetti E, Kolmakov S, Heiskanen P, Vainio P, Lassila V. Panoramic mandibular index and bone mineral densities in postmenopausal women. Oral Surg Oral Med Oral Pathol 1993;75(6):774-779

5 Taguchi A, Ohtsuka M, Tsuda M, et al. Risk of vertebral osteoporosis in post-menopausal women with alterations of the mandible. Dentomaxillofac Radiol 2007;36(3):143-148

6 Lindh C, Horner K, Jonasson G, et al. The use of visual assessment of dental radiographs for identifying women at risk of having osteoporosis: the OSTEODENT project. Oral Surg Oral Med Oral Pathol Oral Radiol Endod 2008;106(2):285-293

7 Henriques JC, Castilho JC, Jacobs R, Amorim JB, Rosa RR, Matai CV. Correlation between hand/wrist and panoramic radiographs in severe secondary hyperparathyroidism. Clin Oral Investig 2013;17(6):1611-1617

8 Jagelaviciene E, Krasauskiene A, Zalinkevicius R, Kubilius R, Vaitkeviciene I. The relationship between the calcaneal bone mineral density and the mental index in post-menopausal females. Dentomaxillofac Radiol 2013;42(4):20120050

9 Dutra V, Yang J, Devlin H, Susin C. Radiomorphometric indices and their relation to gender, age, and dental status. Oral Surg Oral Med Oral Pathol Oral Radiol Endod 2005;99(4):479-484

10 Govindraju P, Chandra P. Radiomorphometric indices of the mandible - an indicator of osteoporosis. J Clin Diagn Res 2014;8(3):195-198

11 Drozdzowska B, Pluskiewicz W, Tarnawska B. Panoramic-based mandibular indices in relation to mandibular bone mineral density and skeletal status assessed by dual energy X-ray absorptiometry and quantitative ultrasound. Dentomaxillofac Radiol 2002;31(6):361-367

12 Wical KE, Swoope CC. Studies of residual ridge resorption. I. Use of panoramic radiographs for evaluation and classification of mandibular resorption. J Prosthet Dent 1974;32(1):7-12

13 Devlin H, Yuan J. Object position and image magnification in dental panoramic radiography: a theoretical analysis. Dentomaxillofac Radiol 2013;42(1):29951683

14 Ghapanchi J, Haghnegahdar AA, Faghih M, et al. Evaluation of mandibular inferior cortex changes in patients candidate for liver and kidney transplantation using panoramic view. J Nephropathol 2017;6:317-323

15 Ledgerton D, Horner K, Devlin H, Worthington H. Panoramic mandibular index as a radiomorphometric tool: an assessment of precision. Dentomaxillofac Radiol 1997;26(2):95-100

16 Nakamoto T, Taguchi A, Ohtsuka M, et al. A computer-aided diagnosis system to screen for osteoporosis using dental panoramic radiographs. Dentomaxillofac Radiol 2008;37(5):274-281

17 West SL, Lok CE, Langsetmo L, et al. Bone mineral density predicts fractures in chronic kidney disease. J Bone Miner Res 2015;30(5):913-919

18 Cakur B, Dagistan S, Sahin A, Harorli A, Yilmaz A. Reliability of mandibular cortical index and mandibular bone mineral density in the detection of osteoporotic women. Dentomaxillofac Radiol 2009;38(5):255-261

19 Dagistan S, Miloglu O, Caglayan F. Changes in jawbones of male patients with chronic renal failure on digital panoramic radiographs. Eur J Dent 2016;10(1):64-68

20 Taguchi A, Sugino N, Miki M, et al. Detecting young Japanese adults with undetected low skeletal bone density using panoramic radiographs. Dentomaxillofac Radiol 2011;40(3):154-159

21 White SC. Oral radiographic predictors of osteoporosis. Dentomaxillofac Radiol 2002;31(2):84-92

22 Koizumi M, Komaba H, Nakanishi S, Fujimori A, Fukagawa M. Cinacalcet treatment and serum FGF23 levels in haemodialysis patients with secondary hyperparathyroidism. Nephrol Dial Transplant 2012;27(2):784-790

23 Bhatnagar S, Krishnamurthy V, Pagare SS. Diagnostic efficacy of panoramic radiography in detection of osteoporosis in post-menopausal women with low bone mineral density. J Clin Imaging Sci 2013;3:23

24 Schwarz S, Trivedi BK, Kalantar-Zadeh K, Kovesdy CP. Association of disorders in mineral metabolism with progression of chronic kidney disease. Clin J Am Soc Nephrol 2006;1(4):825-831

25 Watanabe PC, Faria V, Camargo AJ. Multiple radiographic analysis (systemic disease): dental panoramic radiography. J Oral Health Dent Care 2017;1:7

26 Celenk C, Celenk P. Relationship of mandibular and cervical vertebral bone density using computed tomography. Dentomaxillofac Radiol 2008;37(1):47-51 
27 Yüzügüllü B, Gulsahi A, Imirzalioglu P. Radiomorphometric indices and their relation to alveolar bone loss in completely edentulous Turkish patients: a retrospective study. J Prosthet Dent 2009;101(3):160-165

28 Knezović Zlatarić D, Celebić A, Lazić B, et al. Influence of age and gender on radiomorphometric indices of the mandible in removable denture wearers. Coll Antropol 2002;26(1):259-266
29 Queiroz SM, Amorim AG, Andrade AL, Górdón-Núñes MA, Freitas RA, Galvão HC. Influence of dialysis duration and parathyroid hormone on the clinical and radiographic oral conditions of pre-transplant patients with chronic kidney disease. Braz J Oral Sci 2013;12:125-131 